\title{
As estratégias de cooperação Sul-Sul nos marcos da política externa brasileira de 1993 a 2007
}

\author{
South-South cooperation strategies in Brazilian Foreign Policy \\ from 1993 to 2007
}

MIRIAM GOMES SARAIVA*

Rev. Bras. Polit. Int. 50 (2): 42-59 [2007]

\section{Introdução}

Durante os anos 70 um grupo de países experimentou um crescimento industrial acelerado, junto com uma busca de uma liderança nos âmbitos regional e internacional, assim como reivindicação de novas formulações no ordenamento internacional. A cooperação sul-sul entrou então para a agenda das políticas exteriores tanto de Estados system-affeting (que dispóem de recursos suficientes para, junto com atuação internacional ativa, afetar o andamento de certos temas da política internacional) quanto dos países identificados mais recentemente como "grandes mercados emergentes". 1

No caso do Brasil, embora o país tenha atuado historicamente em marcos de arenas multilaterais de cunho terceiro-mundista, é a partir de 1993, com a ascensão de Itamar Franco, que o país buscará um novo tipo de cooperação sul-sul, nos marcos de uma nova ordem internacional marcada por açōes mais isoladas da dimensão Norte-Sul ou pela volatibilidade das alianças organizadas na defesa de temas específicos.

Segundo Lima ${ }^{2}$ países como o Brasil adotam um comportamento internacional de natureza multifacetada que buscam, ao mesmo tempo, beneficiar-se das possibilidades do sistema internacional, remodelá-lo no papel de liderança visando beneficiar os países do Sul e atuar no contexto regional com uma perspectiva de hegemonia.

Assim, com estratégias de ação, tônicas e protagonismos diferentes, entre 1993 e 2006, a diplomacia brasileira buscou implementar tanto a cooperação sul-sul

\footnotetext{
* Professora e pesquisadora em Relaçōes Internacionais da Universidade do Estado do Rio de Janeiro - UERJ (miriamsaraiva@terra.com.br).

1 Com base em parte em escritos de R. Keohane, LIMA, Maria Regina Soares de. A política externa brasileira e os desafios da cooperação sul-sul. Revista Brasileira de Política Internacional Ano 48 n. 1. Brasília, Ibri, 2005, oferece estas duas interpretaçōes para os países como o Brasil e Índia.

2 LIMA, Maria Regina Soares de. A economia política da política externa brasileira: uma proposta de análise. Contexto Internacional Ano 6 n. 12. Rio de Janeiro, IRI-PUC/RJ, jul./dez 1990, p. 17.
} 
mais tradicional com os vizinhos do continente sul-americano quanto com países considerados potências regionais com relativa relevância internacional.

O objetivo deste artigo é analisar as duas vertentes possíveis da cooperação sul-sul adotadas pela política externa brasileira desde 1993 até a atualidade. Por um lado, examinará a política externa brasileira em face da América do Sul: o Mercosul e a cooperação sul-americana em termos mais gerais que, dentro do arco das atuações externas do país, é o tipo de cooperação sul-sul identificada como prioritária. Por outro lado, dedicará algumas reflexōes para a cooperação do Brasil com outros países considerados emergentes e system-affeting, em outros continentes como é o caso da África do Sul, Índia, China e, porque não, da Rússia.

\section{Variáveis que operaram sobre a formulação da política externa}

Na passagem para os anos 90, o mundo assiste ao fim do bipolarismo, dando lugar a uma nova ordem de caráter ocidental. No campo político, esta ordem aponta para a necessidade das sociedades partilharem de normas internas comuns identificadas com o pluralismo democrático.

No campo econômico, o paradigma liberal passou a ser tanto o marco de referência da economia internacional quanto o orientador da execução de políticas de ajustes no interior dos Estados. Em termos produtivos, a transnacionalização progressiva que tomou impulso com os avanços tecnológicos atuou como parte deste processo.

Esta nova ordem colocou, para os países do sul, novos constrangimentos assim como diferentes opçôes internacionais de inserção. Deste grupo de constrangimentos e opções de inserção, três traços tiveram maior impacto sobre a formulação e implementação da política externa brasileira e de sua opção pela cooperação sul-sul.

Em relação ao liberalismo econômico, no caso brasileiro a concorrência global por mercados e investimentos colocou para o país a necessidade de uma reinserção competitiva na economia internacional. Embora o modelo de desenvolvimento baseado na substituição de importaçóes tenha sido superado, o êxito do crescimento econômico havia proporcionado a organização de setores desenvolvimentistas e protecionistas fortes e estáveis assim como gerado uma estrutura industrial diversificada.

Com base nesta dicotomia, desde o início dos anos 90, existe no Brasil certo equilíbrio entre um pensamento liberal recente e outro mais nacionalista e desenvolvimentista sobre os rumos da estratégia de desenvolvimento a ser adotada. Isto levou, na prática, a um processo de "liberalização condicionada". ${ }^{3}$ Houve uma

3 VEIGA, Pedro da Motta. O policy making da política comercial no Brasil: os caminhos da transição. in: El proceso de formulación de la política comercial. Nivel uno de um juego de dos niveles: Estudios de países em el Hemisfério Occidental. Banco Interamericano de Desarrollo/Munk Centre/Inter-American Dialogue, March, 2002. (Documento de divulgación 13), p. 18. 
mudança de paradigma estruturador da economia nacional e características próprias do liberalismo foram implementadas embora de forma gradual e descontínua.

Em termos produtivos, a transnacionalização progressiva atuou como parte deste processo. O peso do avanço tecnológico como variável da produção criou um abismo ainda maior entre os países mais e os menos desenvolvidos. O novo cenário multilateral modificou a inserção internacional dos países menos desenvolvidos com geometrias variáveis na composição dos grupos de atuação na esfera internacional.

A defesa da democracia como roteiro para as novas formas de inserção e adequação internacionais sugeridas para os países emergentes também teve impacto no caso da política externa brasileira. A aceitação da universalidade do valor da democracia ocidental colocou-se como mecanismo de adesão à idéia básica do Ocidente de defesa do regime democrático e atuou como canal para novos espaços de atuação.

No continente sul-americano, o fim da Guerra Fria, a redução das opçôes valorativas disponíveis, o relaxamento das tensões e a solução dos conflitos centroamericanos contribuíram para que a Organização dos Estados Americanos (OEA) reforçasse sua posição e tivesse sua estrutura, funções e objetivos repensados. Buscou adaptar-se à nova dinâmica das relaçôes interamericanas colocandose desafios como a defesa da democracia, o fortalecimento da governabilidade democrática e uma nova concepção da segurança hemisférica.

Com base neste novo papel, a OEA refinou suas definiçôes de democracia e não-intervenção e implementou uma série de iniciativas em relação a sua proteção. Segundo Villa, ${ }^{4}$ "o impacto de uma visão emergente do mundo revelou-se para os formuladores de politica externa brasileira ... como um mapa do caminho cognitivo de aumento de ganhos relativos na região sul-americana em aspectos como integração regional e desenvolvimento, agenda de segurança regional e imagem política regional".

$\mathrm{Na}$ nova percepção da diplomacia brasileira, tomar como marco normativo a defesa da democracia facilitaria ao país atingir as metas de desenvolvimento visadas. Isto favoreceu então uma pequena inflexão na tradição não-intervencionista da política externa brasileira com vistas a se adaptar mais aos novos padrões da política internacional.

Por fim, a opção pelo regionalismo, que se traduz desde formas superficiais de cooperação entre países, até experiências mais profundas de união aduaneira ou mesmo de um mercado comum, foi uma opção importante de inserção externa. O processo de liberalização da economia internacional e de apoio aos princípios democráticos conviveu com recuperação e avanços das experiências de integração regional.

Em termos internacionais, o regionalismo teve um papel importante em um novo modelo de integração adaptado ao padrão econômico liberal, considerado

4 VILLA, Rafael. Brasil: política externa e a agenda democrática na América do Sul. Trabalho apresentado no $4^{\circ}$ Encontro Nacional da ABCP. Rio de Janeiro, PUC-Rio, 21-24/jul 2004, p. 6. 
como uma forma de aumentar a competitividade econômica e de enfrentar desafios e pressōes tanto internas quanto externas resultantes da economia globalizada.

No âmbito latino-americano, as experiências de integração regional experimentaram avanços, através de esquemas sub-regionais. Durante os anos 90, houve uma retomada de processos de integração já existentes, junto com a formação do Mercosul. Estes novos blocos, ao contrário do modelo de integração proposto pela Comissão Econômica para a América Latina e o Caribe (Cepal) nos anos 50, caracterizaram-se pela abertura para o exterior através da liberalização das economias e, ao mesmo tempo, buscaram tornar-se mais atrativos para o capital externo.

No campo político, em 1986, foi formado o Grupo do Rio que, nos anos 90, experimentou um desenvolvimento incorporando novos membros e atuando como fórum alternativo de articulação de políticas para os países latino-americanos.

Internamente, a crise na estratégia de desenvolvimento e os problemas inflacionários do início da década - assim como a ameaça de marginalização da região em relação ao comércio internacional e a fluxos financeiros - incentivaram os agentes econômicos a buscarem soluções de desenvolvimento e de inserção externa através de um processo de integração. A integração regional vista como um canal de inserção na economia internacional converteu-se em um mecanismo importante no arco das ações externas brasileiras.

\section{Traços gerais da política externa}

No início dos anos 90, diversas políticas externas de países da região experimentaram transformações como consequiência das mudanças ocorridas internamente e na ordem internacional. No caso do Brasil, as modificações em sua política exterior não se deram de forma abrupta ou linear.

A trajetória interna de avanços e recuos nas transformações econômicas - assim como o forte predomínio da chancelaria e suas tradições no processo de formulação da política exterior - contribuiu para que o processo fosse mais lento. A chegada de Collor de Mello à Presidência esteve acompanhada de uma crise de paradigma que pôs em xeque os princípios da política externa adotada até então, mas que não foi capaz de consolidar um novo conjunto de princípios.

O Itamaraty é uma corporação forte, com uma burocracia que historicamente concentra o processo de formulação da política externa. Esta centralização, se tradicionalmente contribuiu para um comportamento mais estável, criou certas dificuldades de renovação e de adaptação à nova realidade nacional (democratização e abertura econômica) e internacional.

Contribuiu, assim, para que a diplomacia enfrentasse dificuldades em negociaçôes ou em representar distintos interesses sociais e concorreu para o ritmo mais lento das inflexōes experimentadas pela política externa.

A crise de paradigma não abriu espaço para a consolidação de um consenso substitutivo, mas sim de duas correntes com diferentes visōes sobre a inserção internacional do país e sobre temas da cooperação sul-sul. 
A primeira, de caráter mais autonomista, manteve mais os elementos do paradigma globalista seguido até então. Defende uma projeção mais autônoma do Brasil na política internacional; tem preocupaçōes de caráter político-estratégico dos problemas Norte/Sul; dá maior destaque à perspectiva brasileira de participar do Conselho de Segurança das Nações Unidas; e busca um papel de maior liderança brasileira na América do Sul. O destaque que dá para a cooperação com países do Sul é evidente.

A segunda, sem abrir mão das reivindicaçōes da primeira, procura dar maior importância ao apoio do Brasil aos regimes internacionais em vigência. Defende uma inserção internacional do país a partir de uma soberania compartilhada e da autonomia pela participação (onde valores globais devem ser defendidos por todos). Busca na América do Sul uma liderança mais discreta. ${ }^{5}$ Em função de seu apoio aos valores da ordem internacional atual, de caráter liberal, este grupo é identificado por analistas de política externa como "liberais".

O governo Collor, mais liberal, foi seguido pela administração autonomista de Itamar Franco e o governo de Cardoso buscou um comportamento que conjugasse traços das duas visōes. A administração Lula, por fim, recolocou como eixo da política externa a corrente autonomista vinculada aos padróes tradicionais de política externa.

Um elemento comum importante às duas correntes que atuou como incentivo para a cooperação com países do Sul foi a manutenção, por parte da diplomacia brasileira, da crença que sustenta que o Brasil deve ocupar um lugar especial no cenário internacional em termos político-estratégicos. No período de Itamar Franco, quando a política externa recuperou a preponderância de seus pressupostos tradicionais de vertente autonomista, apoiou-se em uma perspectiva que identificava a ordem internacional como cenário de polaridades indefinidas. ${ }^{6}$

Defendia que a principal potência, apesar de sua posição destacada de liderança, buscaria adaptar-se às necessidades dos parceiros de maior relevância e de outros menores, entre os quais se encontrava o Brasil. ${ }^{7}$ Como conseqüência, a diplomacia brasileira procurou desdramatizar as relaçôes com os Estados Unidos evitando tanto alianças incondicionais quanto enfrentamentos. ${ }^{8}$

No início do governo de Cardoso a inflexão mais relevante foi a aceitação do novo conceito de soberania compartilhada, diferente do conceito clássico de

\footnotetext{
5 Sobre o "desejo de autonomia" e a perspectiva de adesão do Brasil aos regimes internacionais, ver PINHEIRO, Letícia. Traídos pelo Desejo: um ensaio sobre a teoria e a prática da política externa brasileira contemporânea. Contexto Internacional, vol. 22 n. 2. Rio de Janeiro, IRI-PUC/RJ, jul./dez 2000, p.305-334.

6 LAFER, Celso e FONSECA JR., Gelson. Questōes para a Diplomacia no Contexto Internacional de Polaridades Indefinidas. In: FONSECA JR., Gelson \& NABUCO DE CASTRO, Sérgio (orgs.), Temas de Política Externa Brasileira II, vol. I. São Paulo, Paz e Terra/Ipri, 1994, p. 49-77.

7 SARAIVA, Miriam Gomes e TEDESCO, Laura. Argentina e Brasil: políticas exteriores comparadas depois da Guerra Fria. Revista Brasileira de Politica Internacional Ano 44 n.2. Brasília, Ibri, jul./dez.2001. p.126-150.

8 Ver LIMA, Maria Regina Soares de \& HIRST, Mônica. O Brasil e os Estados Unidos: dilemas e desafios de uma relação complexa. In: FONSECA JR., Gelson \& NABUCO DE CASTRO, Sérgio (orgs.), Temas de Politica Externa Brasileira I- V.2. São Paulo, Paz e Terra, 1994.
} 
soberania. ${ }^{9}$ Esta visão identificava um mundo marcado por valores universais, onde os Estados estariam sujeitos às normas oriundas dos regimes internacionais.

Neste quadro, os Estados Unidos seriam um país com mais recursos de poder, mas que necessitariam da adesão de outras potências para a gestão desta ordem. Em termos práticos, a política externa brasileira manteve, em relação ao parceiro, um baixo perfil em termos políticos, e divergências em temas tanto da organização do comércio internacional quanto relativos ao continente americano.

\section{Brasil e a Cooperação Sul-Sul com América do Sul}

Em termos da cooperação com países da América do Sul, cabe destacar as iniciativas brasileiras de estruturação de mecanismos de cooperação com os países da região como um todo e, como principal dimensão da política de cooperação do Brasil, o relacionamento no interior do Mercosul com destaque para a cooperação Brasil-Argentina.

\section{A construção de uma liderança em face da região}

A estratégia de construção de liderança por parte da diplomacia brasileira na América do Sul foi seguida durante todo o período, mas com diferentes gradaçôes. Durante o governo de Franco, a aproximaçãa com os países vizinhos, já dentro dos marcos de uma cooperação sul-sul, foi intensificada, podendo ser enquadrada no que Myers define como "Estado aspirante a hegemônico" no contexto regional. ${ }^{10}$

Em termos da cooperação econômica, durante o governo de Franco, a perspectiva de se criar uma Área de Livre Comércio Sul-Americana (Alcsa) foi colocada em relevo em detrimento do Mercosul ${ }^{11}$. Neste caso, o Brasil ocuparia uma posição central de liderança no bloco, mas o projeto não prosperou.

O modelo de atuação brasileiro diante de situações de crise na região foi de não-intervenção, baseado em preceitos tradicionais da diplomacia brasileira em termos de percepções da segurança internacional e de conceitos clássicos da política internacional, que foram mantidos a despeito de todas as mudanças ocorridas no cenário internacional. No interior da Organização dos Estados Americanos (OEA), a postura brasileira foi de defender uma posição menos intervencionista.

No que diz respeito à interação com os Estados Unidos em temas da cooperação política na América do Sul, não havia coincidência de opiniōes e, portanto, não se

9 SILVA, Alexandra de Mello e. A política externa em transição: rumo a um novo paradigma? Net Work, vol.8 n. 3. Rio de Janeiro, CEA's/Ucam, jul/set 1999, p. 6.

10 MYERS, D. (1991). Threat perception and strategic responses of regional hegemons: A conceptual overview. in D. Myers (ed.), Regional Hegemons: Threat perceptions and strategic responses. Boulder/San Francisco, Westview Press, citado por SENNES, Ricardo U. Potência média recém-industrializada: parâmetros para analisar o Brasil. Contexto Internacional, vol. 20 n. 2. Rio de Janeiro, IRI-PUC/RJ, jul/dez p. 390.

11 CERVO, Amado (1998). Multilateralismo e integración: evolución del pensamiento diplomático brasileño. Ciclos, Año VIII, n. 14-15. Buenos Aires, Instituto de Investigaciones en Historia Económica y Social/UBA, 1er. Semestre 1998, p. 205-226. 
colocava a possibilidade de se construir alguma atuação articulada de longo prazo, porém, em função da desdramatização das relações, o Brasil tampouco buscou enfrentamentos. ${ }^{12}$

Durante o mandato de Cardoso, a diplomacia iniciou uma modesta revisão do comportamento brasileiro perante a região. Buscou construir sua liderança na área a partir do binômio segurança e estabilidade democrática, estabelecendo vínculos fortes com os países vizinhos e atuando como mediador em situações de crise quando chamado para tal.

A partir de uma perspectiva de apoio aos regimes internacionais, a aceitação da idéia da democracia como valor universal contribuiu para que a diplomacia brasileira estabelecesse um consenso em torno da vinculação entre democracia, integração regional e perspectivas de desenvolvimento nacional. ${ }^{13}$ Assim, sem abrir mão dos princípios da não-intervenção, buscou incluir em sua agenda a defesa da democracia e atuar em face de cada caso de crise.

No campo econômico, a idéia de formação da Alcsa foi abandonada. Ao mesmo tempo, no que tange à construção da Área de Livre Comércio das Américas (Alca) proposta pelos Estados Unidos, a diplomacia brasileira criou obstáculos, dando preferência a experiências sub-regionais. Por outro lado, foi dado início ao movimento de construção de uma comunidade sul-americana de nações, de caráter mais político e abrangente que o projeto da Alcsa.

Em 2000, houve a primeira reunião dos países sul-americanos em Brasília, com vistas a formar a Comunidade Sul-Americana de Nações, onde as idéias principais discutidas foram integração econômica e infra-estrutura da região, assim como o reforço dos regimes democráticos.

No governo de Lula, com o fortalecimento da corrente autonomista, a construção de uma liderança na região é defendida com mais vigor e busca aprofundar o comportamento que já seguido na gestão de Cardoso, mas de forma mais ativa.

A diplomacia brasileira incluiu em sua agenda um projeto mais claro de construção de uma liderança regional articulado à segurança regional, à defesa da democracia, aos processos de integração regional e às perspectivas de desenvolvimento nacional.

Os exemplos mais relevantes da diplomacia brasileira como mediador em situações de crise foram, primeiramente, a proposta de formação do Grupo de Amigos da Venezuela, com vistas a acompanhar os embates entre o governo venezuelano e a oposição na questão do plebiscito (e depois nos atritos entre Venezuela e Colômbia).

12 SENNES, Ricardo U. Potência média recém-industrializada: parâmetros para analisar o Brasil, op. cit., p.404, assinala como potências médias como o Brasil em geral buscam estabelecer relações bilaterais de baixo perfil com as grandes potências com vistas a manter-se livres de sua influência em temas tanto internos quanto regionais. 13 Ver VILLA, Rafael. Brasil: política externa e a agenda democrática na América do Sul, op. cit. 
Em seguida, buscou assumir o papel de mediador entre o governo de Hugo Chávez e os países da região. A tentativa brasileira de apaziguar a situação equatoriana por fora do âmbito da OEA também foi importante. Por fim, a mediação que a diplomacia presidencial brasileira buscou exercer na crise boliviana.

A participação brasileira nas Forças de Paz do Haiti também se vincula às iniciativas brasileiras de consolidar sua liderança na região e reforçar a cooperação sul-sul. Neste caso, Brasil lidera uma força de imposição de paz da Organização das Nações Unidas (ONU) composta por tropas de diversos países da região.

A posição brasileira de mediador e de líder de uma força de imposição da paz é já uma maior adequação aos novos parâmetros da ordem internacional se comparada com a idéia da não-intervenção aplicada plenamente em termos históricos.

Segundo o chanceler Celso Amorim, "O Brasil sempre pautou pela nãointervenção nos assuntos internos de outros Estados ... Mas ... o preceito da nãointervenção deve ser visto à luz de outro preceito, baseado na solidariedade: o da não indiferença." 14 É com base nesta formulação que a diplomacia desempenha um papel ativo com vistas a solução de crises regionais. ${ }^{15}$

Outra esfera de atuação importante foi a Comunidade Sul-Americana de Nações (CASA). A partir da eleição de Lula, a diplomacia brasileira concentrou esforços mais diretos na sua implementação.

As idéias de maior integração econômica, de infra-estrutura e defesa dos regimes democráticos seguiram sendo foco central de discussão. Em 2004, a CASA foi formalmente constituída e seu primeiro desempenho importante foi uma cúpula entre os sul-americanos e os países da Liga Árabe, organizada pelo governo brasileiro em 2005.

A atuação brasileira nesta área conviveu também com algumas tensões. A partir do incremento de sentimentos nacionalistas, alguns países vizinhos reivindicam concessões brasileiras no campo econômico.

A nacionalização dos hidrocarbonetos levada adiante pelo governo boliviano, embora tenha afetado a Petrobrás, foi digerida pelo governo brasileiro e a diplomacia adotou uma posição pragmática e de baixo perfil. A ascensão do governo de Hugo Chávez na região com um projeto alternativo de liderança coloca um dilema para a política externa brasileira: como incluir a Venezuela no projeto brasileiro de integração e evitar que o presidente Chávez defina o ritmo do processo.

Como parte do projeto brasileiro e em resposta a estas reivindicações, dão-se passos importantes no sentido de articular o projeto de liderança nacional na região (democracia/integração regional/perspectivas de desenvolvimento nacional) que começam a se refletir em uma maior disposição brasileira de arcar com alguns custos da integração. A reeleição de Lula devolveu sua legitimidade e a diplomacia

14 Citado por OLIVEIRA, Marcelo Fernandes de. Elites econômicas e política externa no Brasil contemporâneo. São Paulo, IEEI/mimeo, 2005, p. 21-22.

15 OLIVEIRA, Marcelo Fernandes de. Elites econômicas e política externa no Brasil contemporâneo. op. cit., p. 21. 
presidencial ativa vem sendo retomada com mais vigor ao comportamento brasileiro vis a vis a região.

\section{Os casos do Mercosul e da cooperação com a Argentina}

O Mercosul é a experiência de integração mais importante da política externa brasileira e abriu uma nova etapa em sua formulação e implementação. O Tratado de Assunção foi assinado em 1991, a partir dos avanços da cooperação entre Brasil e Argentina desenvolvidos desde 1985.

Embora a cooperação entre ambos fosse orientada mais para os campos político e de infra-estrutura, o Tratado deu mais impulso para a área comercial em função da coincidência de projetos liberais de abertura entre os governos de Collor e de Menem. ${ }^{16}$

A visão mais pragmática do processo de integração então predominante acreditava que a união aduaneira favoreceria a articulação do projeto nacional de desenvolvimento contribuindo para gerar uma economia de escala especializada.

Em relação à inserção externa, o bloco poderia contribuir como pólo de atração de comércio e investimentos privados. Em termos da "construção de liderança” brasileira na região, o Mercosul poderia atuar como elemento condicionador das economias de países vizinhos. Desde a perspectiva argentina, o governo de Menem via no Brasil um parceiro no campo econômico, enquanto deixava a posição de principal parceiro político para os Estados Unidos. ${ }^{17}$

$\mathrm{Na}$ evolução do processo de cooperação, o comércio foi na prática um dos setores onde a integração avançou mais. As assimetrias entre as economias dos sócios e as diferenças nas políticas cambiais obstaram uma aproximação maior em termos de coordenação macroeconômica. A preservação da autonomia no que tange às decisões internas de política econômica era considerada mais relevante.

A presidência de Franco, de corte mais autonomista, buscou um projeto de integração dando mais importância à formação da Alcsa. Percebendo a integração sul-americana sob a liderança brasileira como prioridade, a corrente autonomista via como importante uma ampliação do bloco através da entrada de novos Estados ou dos esforços de se formar uma área de livre comércio de toda a América do Sul.

O Mercosul, por seu turno, poderia atuar como um instrumento capaz de proporcionar ao Brasil um melhor posicionamento regional, assim como atuar na esfera comercial como elemento capaz de abrir caminho para a formação da área de livre comércio.

Mas a integração nos marcos do Mercosul foi se impondo (enquanto o projeto da Alcsa ficou no discurso). O bloco foi assumindo um papel cada vez

16 Os governos anteriores de Sarney e Alfonsín tinham opções mais desenvolvimentistas. Por isto, muitos autores chamam a opção comercialista de "abandono dos princípios originários da cooperação".

17 SARAIVA, Miriam Gomes e TEDESCO, Laura. Argentina e Brasil: políticas exteriores comparadas depois da Guerra Fria, op. cit. 
mais importante na política externa brasileira, sobretudo em termos comerciais. No final de 1994, foi assinado o Protocolo de Ouro Preto que marcou o início da união aduaneira e deu ao bloco uma personalidade jurídica para a negociação de acordos internacionais. Diversos setores econômicos internos foram se engajando no processo, outorgando-lhe maior consistência.

Durante a gestão de Cardoso, em 1999, o Mercosul viveu uma grave crise em função da desvalorização da moeda brasileira e dos efeitos negativos desta medida sobre a economia argentina. A falta de mecanismos institucionais capazes de solucionar os problemas intra-bloco abriu espaços para que problemas nacionais criassem obstáculos para sua evolução e tornassem claros os conflitos em seu interior. ${ }^{18}$

O desenvolvimento do processo de integração, assim como a solução das divergências entre seus Estados membros, ficou nas mãos das lideranças nacionais. O governo argentino, em face da desvalorização do real, impôs barreiras alfandegárias para produtos brasileiros. O governo brasileiro, por seu turno, afastou-se do processo de integração mantendo um baixo perfil até o início da administração de Fernando de la Rúa.

Durante o governo de Lula, a atuação brasileira no Mercosul vem sendo marcada por movimentos diferentes, oriundos de distintas correntes de pensamento que compõem o governo. A primeira, já vista, refere-se à perspectiva autonomista que prioriza a liderança brasileira na América do Sul como um todo.

Esta perspectiva impulsionou a assinatura de acordo de associação com os países da Comunidade Andina e a candidatura da Venezuela como sócio pleno. Ao mesmo tempo, busca manter um equilíbrio econômico no interior do Mercosul que favoreça os projetos brasileiros de desenvolvimento industrial e projeção econômica.

A segunda diz respeito à visão de acadêmicos e lideranças pró-integração, que propóe um aprofundamento do processo em termos políticos e sociais e busca abrir espaços para avanços de sua institucionalização. A ratificação e implementação do Protocolo de Olivos e a formação do Parlamento do Mercosul são resultantes dos esforços de institucionalização do bloco deste grupo.

O Fundo para a Convergência Estrutural do Mercosul foi criado, mas ainda faltam detalhes sobre seu funcionamento. No entanto, os desequilíbrios econômicos regionais internos ao Brasil dificultam que o país exerça o papel do paymaster no bloco ou na região e absorva custos dos parceiros menores.

O Mercosul atua também como canal de cooperação sul-sul de caráter interregional. No que se refere às relaçóes econômicas externas, o bloco desempenha um papel fundamental nos diálogos com outros grupos de países. Sua atuação coletiva ganhou destaque depois da assinatura do Protocolo de Ouro Preto,

18 ONUKI, Janina. A fragilidade institucional do Mercosur. Carta Internacional, Ano. 9, n. 98. São Paulo, 2001, p. 13. 
quando foram negociados diversos acordos. Isto favoreceu a estratégia brasileira de maiores contatos com outros mercados sul-americanos.

Em setembro de 1994, seus membros aprovaram um documento que propunha incentivar a liberalização do comércio entre os países da América do Sul. As negociações de associação com Chile e Bolívia resultaram na assinatura de acordos com estes países em 1996.

Em 1998 foi assinado um acordo marco para negociar uma área de livre comércio com a Comunidade Andina. Em 2003, foi firmado um acordo de associação nos moldes do acordo assinado com Chile e com Peru e, em 2004, foi assinado também com Venezuela, Colômbia e Equador. ${ }^{19}$ As negociações - não concluídas - para a formação da Alca foram levadas em conjunto pelos países membros do bloco.

Nos marcos do Mercosul, o eixo bilateral Brasil/Argentina de cooperação é considerado estratégico em termos políticos pelo Brasil. A dinâmica política do grupo repousa sobre esta interação.

A perspectiva de uma aliança entre Argentina e Brasil no que diz respeito a uma atuação frente aos temas da política regional e internacional é mencionada há muitos anos. Em meados da década de 90, foi criado o "Mercosul político" com o objetivo, entre outros, de buscar posiçóes internacionais comuns entre os países membros.

No entanto, as políticas externas dos países membros seguiram sendo consideradas área sensível e vistas por ambos como questão de soberania nacional. Segundo Pinheiro, ${ }^{20}$ no caso das relações do Brasil com países vizinhos, o desejo de autonomia "se utiliza da concepção (grociana) para a satisfação de sua busca por poder".

Assim seus espaços de atuação externa em termos individuais e do aumento de sua projeção no cenário internacional não devem ser obstados por qualquer "partilha de soberania" (concepção realista). Como agravante, desde a formação do Mercosul, a corporação diplomática brasileira tem uma visão da Argentina como sócio menor e as mudanças freqüentes que ocorrem na política externa argentina geram desconfiança.

Desde a perspectiva da diplomacia argentina, existe uma permanente indefinição sobre o papel exato que Brasil deve ter na política externa do país ${ }^{21}$ e parte desta diplomacia mostra-se sensível a qualquer sinal de proeminência do Brasil no interior do Mercosul. Identifica-o como país que busca sempre mais poder na esfera internacional em detrimento dos outros parceiros de bloco.

19 O Acordo Marco com a União Européia não é objeto de estudo deste artigo, pois não representa a cooperação sul-sul. Outros acordos de cooperação sul-sul serão vistos na parte seguinte.

20 PINHEIRO, Letícia. Traídos pelo Desejo: um ensaio sobre a teoria e a prática da política externa brasileira contemporânea, op. cit., p. 323.

21 RUSSELL, Roberto. Política exterior y veinte años de democracia: un primeer balance. In NOVARO, M. \& PALERMO, V. (comps.), La historia reciente. Argentina en Democracia. Buenos Aires, Edhasa, 2004. p. 257-269 
A eleição em poucos meses de Lula e de e Kirchner abriu espaços para a construção de uma parceria mais sólida no campo político. Mas, depois de um início de aproximaçôes, em meados do primeiro mandato de Lula, as relações viveram uma crise.

O investimento brasileiro na integração sul-americana e na construção de uma liderança regional provocaram reaçôes contrárias no governo argentino. Neste contexto, a diplomacia brasileira buscou manter um baixo perfil para não comprometer o eixo bilateral. A partir do final de 2005, a Argentina adotou um comportamento mais conciliador e a crise foi superada.

A incorporação da Venezuela ao Mercosul como sócio pleno deve dar um novo equilíbrio interno. A opção do governo argentino de estabelecer uma aliança com Hugo Chávez com vistas a limitar avanços brasileiros na construção de uma liderança regional já é visível.

A necessidade da diplomacia brasileira de conviver com um dirigente também com pretensões de construção de liderança na região - com divergências de interesses e estilo, e com percepção e compreensão diferenciadas do cenário regional - pode dificultar a construção de uma aliança política mais sólida.

\section{Outras formas de cooperação sul-sul}

Em termos gerais, a política externa brasileira durante o período buscou aproximação maior com as consideradas potências médias de grande porte, com destaque para Índia, China, África do Sul e - embora não pertencente ao que se entende por Sul - Rússia. Durante o governo de Franco e na política externa de Lula, esta prática se fez mais presente.

Desde 1993, a cooperação sul-sul com estes países assume dois modelos distintos, ainda que caminhem juntos. Por um lado, esta cooperação foi levada adiante pela diplomacia brasileira através de negociações comerciais nos marcos do Mercosul.

Neste caso, o Brasil buscou a assinatura de acordos comerciais do bloco com países considerados do Sul em termos individuais ou em grupo. Por outro lado, o Brasil buscou aproximar-se desses países em termos individuais tanto na arena internacional (com destaque para as negociações da Organização Mundial do Comércio) quanto comvistasaestabelecercomestesachamada "parceiraestratégica".

Nestes casos, a autonomia de política exterior no que diz respeito aos parceiros do Mercosul foi resguardada e a possibilidade de formulação de um comportamento comum entre os Estados do bloco não foi contemplada.

Historicamente, existem experiências de atuações conjuntas de países do Sul nos marcos do Grupo dos 77, mas a base mais sólida desta aproximação a partir da percepção da corrente autonomista do Itamaraty é a crença de que estes países teriam características semelhantes ao Brasil e com interesse no reordenamento do sistema internacional. 
Estes países, embora experimentem condicionamentos externos sobretudo em termos econômicos, teriam uma parcela de autonomia na formulação de suas ações internacionais e, com o fim do bipolarismo, aumentam sua capacidade de negociação na esfera internacional. ${ }^{22}$. Ademais, tendem a buscar uma cooperação internacional como forma de se contrapor a ações unilaterais de grandes potências.

Foi no governo de Franco, quando a vertente autonomista do Itamaraty ocupou mais espaços, que a idéia de desenvolver formas de cooperação com países emergentes extra-regionais tomou força.

Documento do Itamaraty, de 1993 (sobre a Rússia, mas aplicável também aos demais), destaca que "são países que não estão integrados estruturalmente a áreas mais amplas, e que tampouco ocupam um dos pólos centrais, vêem na globalização a possibilidade de realizar sua condição de potência e de não serem levados a optar por um esquema de associação periférica a uma das três grandes áreas .. .são os candidatos naturais a ter lugar de estaque na nova ordem mundial".

Semelhanças como as "dimensöes continentais", "reconhecida importância regional", "população", "produtointernobruto", "recursosnaturais", "regimedemocrático". (exemplos da Índia e da África do Sul). ${ }^{23}$ Neste caso, a formação de "parcerias estratégicas” entre o Brasil e estes Estados passou a ser uma opção relevante.

Em novembro de 1993, iniciou-se o incremento das relações entre Brasil e China com a visita do presidente Zemin ao Brasil com o objetivo de se organizar uma "parceria estratégica" em setores de infra-estrutura e tecnologia.

Nesta visita, foi assinado um protocolo de cooperação em pesquisa espacial. ${ }^{24}$ Houve esforços para o fortalecimento das relações com a Índia a partir de uma maior articulação entre as atuações dos dois países nos foros multilaterais no tratamento de temas da política e do comércio internacionais.

Neste caso, a perspectiva de se atuar conjuntamente em foros multilaterais de forma que maximizasse suas ações deu base às ações brasileiras. Foi assinado também um acordo na área científica e tecnológica entre os dois países em 1993. Mas estes esforços, naprática, nãosetraduziramnestemomentoemumincrementosignificativo.

No que se refere à África do Sul, em 1994 com o fim do apartheid, inaugurouse uma nova etapa nas relaçôes entre os dois países, mas que, como no caso da Índia, não mostrou resultados ainda na gestão de Franco.

No que diz respeito às relaçôes com a Rússia, em 1994, o chanceler Celso Amorim viajou ao país iniciando conversações com vistas à formação de um organismo de consulta entre os dois países, quando assinou um tratado de parceria

22 SENNES, Ricardo Ubiraci (1998) Potência média recém-industrializada: parâmetros para analisar o Brasil. Apresenta uma análise muito interessante das classificaçôes sobre estes países.

23 "O repensar do Itamaraty e da Política Externa Brasileira”, citado por BARROS NETTO, Sebastiāo do Rego. O Brasil e a Rússia. In: FONSECA JR., Gelson \& NABUCO DE CASTRO, Sérgio (orgs.), Temas de Política Externa II - volume 2. Brasília, Fundação Alexandre de Gusmão/São Paulo, Editora Paz e Terra, 1994, p. 134. 24 Ver HIRST, Mónica e PINHEIRO, Letícia. A política externa do Brasil em dois tempos. Revista Brasileira de Política Internacional, Ano 38 n. 1, Brasília, Ibri, 1995, p. 5-23. 
que buscava qualificar as relações entre ambos como "parceria estratégica" ${ }^{25}$ Em termos comerciais, o comércio seguiu em patamares baixos.

Embora durante o governo de Cardoso o ritmo deste movimento tenha diminuído em função da predominância da corrente liberal no interior do Itamaraty, o processo de aproximação com estes países teve seqüência com destaque inicialmente para o campo comercial.

No final de sua gestão, a nova conjuntura internacional após o 11 de setembro colocou a necessidade da diplomacia brasileira repensar sua inserção internacional reforçando a vertente multilateral e a aproximação com outros países do Sul.

Em 1996, foi assinado o Acordo de Pretória e Cardoso visitou a África do Sul, quando são iniciadas as negociações comerciais entre o Mercosul e o país. Em dezembro de 2000, foi assinado um acordo marco entre ambos orientado para a criação de uma área de livre comércio. Em 2003, já no governo Lula, foi decidida a incorporação dos outros países da Uniāo Aduaneira da África Austral.

Mais no final do mandato, foi estabelecida uma aliança com a África do Sul e a Índia na questão da propriedade intelectual na área de farmacêutica. O contencioso das patentes foi levado adiante pelo Brasil e África do Sul contra o governo norte-americano, defendendo a possibilidade de os paises incentivarem a produção interna de remédios contra o HIV a custos menores.

Houve êxito à medida que incorporou a Índia, que dentro dos benefícios da "fase de transição" do Acordo Trips produzia e vendia medicamentos similares aos de indústrias norte-americanas a custos menores. ${ }^{26}$ Os governos brasileiro e sul-africano conseguiram o apoio de outros países africanos e puderam passar a comprar o coquetel anti-HIV da Índia. Esta experiência serviu como modelo exitoso de cooperação nos marcos da cooperação sul-sul frente a um tema multilateral, mas não teve seqüência durante o governo de Lula.

Em relação à China, no início da década, seu mercado passou a ocupar a terceira posição como destino das importações brasileiras, mas novos passos no sentido de construção da "parceria estratégica" não foram dados. Foi apresentado pela diplomacia brasileira um estudo sobre a viabilidade de se negociar um acordo de livre comércio China-Mercosul.

Diferentemente dos outros casos, com a Rússia negociações comerciais não prosperaram. A partir de 1995, o comércio entre ambos experimentou um crescimento relativo, mas mantendo a pouca diversificação produtos exportados. As dimensóes que tiveram maiores avanços foram as de caráter político e de cooperação.

Em 1997, em visita do chanceler Primakov ao Brasil, foram assinados diversos acordos de cooperação em áreas de educação, cultura, ciência e tecnologia

25 Ver Protocolo sobre consultas entre o Ministério de Relaçōes Exteriores da República Federativa do Brasil e o Ministério dos Negócios Estrangeiros da Federação Russa e Tratado sobre sa Relaçōes de Parceria entre a República Federativa do Brasil e a Federação da Rússia (MRE, Brasil, Resenha de Politica Exterior do Brasil n. 75, jul./dez 1994, p. 104-105 e 108).

26 O Acordo Trips previa um período até 2005 para que países em desenvolvimento se incorporassem definitivamente às suas normas. 
e investigações sobre o espaço exterior. ${ }^{27}$ Nesta mesma oportunidade, foi assinada a "Declaração Conjunta de Criação da Comissão de Alto Nível" e, depois de algum tempo, em 2000, em visita do vice-presidente Marco Maciel à Rússia, teve início o funcionamento da comissão.

Os temas mais freqüentes são: o papel das Nações Unidas, os princípios do multilateralismo e do direito internacional, preocupações com a segurança regional e internacional, combate ao terrorismo e busca de um sistema internacional de comércio mais fortalecido e não-discriminatório. Mas a idéia de aproximação de uma Rússia com características parecidas ao Brasil atuou mais como elemento potencial que concreto.

A posse do presidente Lula e o reforço da corrente autonomista deu uma nova direção à política externa brasileira, com vistas a construir uma nova estratégia de inserção internacional do país, mais adequada tanto ao seu papel no mundo quanto aos constrangimentos próprios à "inserção periférica dos países em desenvolvimento". 28

Este movimento deu um novo peso à cooperação sul-sul dentro da política externa brasileira, buscando consolidar um multilateralismo mais favorável a estes países. Buscou, entre outras, recuperar a divisão norte/sul e recolocá-la no centro da política internacional.

Com esta determinação, priorizou uma campanha de reestruturação das Nações Unidas, assim como recolocou a candidatura do Brasil para um assento permanente em seu Conselho de Segurança. Foi formado com a Índia (mais Alemanha e Japão) o Grupo dos candidatos a uma cadeira definitiva do Conselho de Segurança da ONU.

Buscou uma atuação mais ativa de defesa da perspectiva brasileira nas negociações na $\mathrm{OMC}$ em ação conjunta com outros países em desenvolvimento, dando prioridade ao equilíbrio dos benefícios recebidos por países mais desenvolvidos e em desenvolvimento.

O G-20 - formado em 2003 por países como Índia, China e África do Sul tornou-se e seguirá sendo um foro importante de atuação da diplomacia brasileira logrando condicionar os avanços das negociações da OMC à inclusão do tema agrícola, assim como possibilitou ao Brasil ocupar um lugar de global player nestas negociações.

Em termos comerciais, o governo reforçou questôes político-estratégicas adotando um comportamento pró-ativo na área e empreendeu uma política incisiva de busca de mercados.

No que diz respeito às relações do Brasil com Índia e África do Sul, houve muitos avanços. No início da gestão de Lula, a diplomacia brasileira convocou

27 Sobre as relaçôes com a Rússia ver BACIGALUPO, Graciela Zubelzú de. As relaçôes russo-brasileiras pósGuerra Fria. Revista Brasileira de Politica Internacional, Ano 43 n. 2, Brasília, Ipri, 2000.

28 OLIVEIRA, Marcelo F. de. Alianças e coalizões internacionais do governo Lula: a Ibas e o G-20. Revista Brasileira de Politica Internacional, Ano 48 n. 2, Brasília, Ibri, 2005. p. 56. 
uma reunião em Brasília com os chanceleres dos dois países com vistas a dar continuidade à aliança ensaiada no caso do contencioso das patentes.

Lá, foi assinada uma declaração que estabeleceu uma aliança de caráter permanente - o mecanismo é conhecido como Fórum de Diálogo IBAS (Índia, Brasil e África do Sul). Seus objetivos são fortalecer a capacidade dos três países nas negociações internacionais, lutar pela reforma das Nações Unidas, assim como promover a cooperação técnica em diversas áreas.

Nestas iniciativas, a diplomacia mantém uma autonomia em relação aos parceiros do Mercosul embora se beneficie de sua posição na região para ampliar sua projeção internacional.

No campo comercial, em junho de 2003, foi assinado um acordo marco Mercosul-Índia nos mesmos moldes do Acordo assinado com a África do Sul e, em 2005, foi assinado um acordo preferencial. Em tempos recentes, Brasil formou junto com a Índia o chamado G-4, que busca negociar com os estados Unidos e a União Européia uma saída para a Rodada de Doha. ${ }^{29}$

Também foi assinado um acordo preferencial Mercosul-África Austral. Embora seja um comércio pouco expressivo dentro do comércio brasileiro com outros em termos gerais (ficam ambos abaixo de $1 \%$ do total), experimentaram um aumento a partir de $2001 .{ }^{30}$ Nas negociaçôes sobre o meio ambiente, Brasil compôs junto com a Índia a negociação de um Protocolo favorável aos países em desenvolvimento.

A "parceria" Brasil-China também experimentou avanços no período. Em 2004, o vice-primeiro-ministro chinês visitou o Brasil e o presidente Lula, a China, onde foram assinados diversos acordos de cooperação das áreas econômica e tecnológica.

Foi estabelecida uma Comissão de Concertação e Cooperação, semelhante à estabelecida com a Rússia durante a gestão de Cardoso, assim como foi reforçada a "parceria estratégica" mencionada anteriormente.

Foram também iniciados estudos sobre a assinatura de um acordo marco com vistas à negociação de um acordo de livre comércio Mercosul-China (que havia sido proposto no governo anterior), mas que foi obstado pelo fato do Paraguai manter relações diplomáticas com Formosa.

Por fim, no que diz respeito à Rússia, não houve avanços significativos nas relações. Apesar dos discursos e dos mecanismos diplomáticos, as características de inserção internacional da Rússia não se enquadram na categoria das potências médias em função de sua localização geográfica e do relacionamento com sua vizinhança imediata mas, sobretudo, por seu poder militar. A interação da Rússia

29 Até o momento são negociações difíceis e incertas aonde a supressão dos subsídios agrícolas coloca-se como contraparte da redução de barreiras para produtos industrializados.

30 LIMA, Maria Regina Soares de. A política externa brasileira e os desafios da cooperação sul-sul, op. cit., p. $48-49$. 
com os Estados Unidos e com países da União Européia se dá em um nível muito diferente dos casos do Brasil, da Índia e da África do Sul.

Apesar da importância dada à cooperação sul-sul pela política externa de Lula, na prática, os avanços ainda são incipientes. Existem fortes diferenças entre estes países e nem sempre seus interesses são coincidentes.

A China e a Rússia têm uma inserção bem distinta em temas da segurança internacional. De qualquer forma, os esforços continuam e possivelmente até o final do segundo mandato do governo de Lula alguns resultados mais significativos poderão ser identificados.

\section{Considerações finais}

As iniciativas de cooperação sul-sul levadas adiante nos marcos da política externa brasileira desde 1993 ocupam em tempos recentes um papel cada vez mais relevante no arco das ações internacionais do país. Este movimento é decorrente da nova conjuntura internacional multilateral dos anos 90, do tipo de inserção internacional do país, assim como da ascensão, dentro do Itamaraty, da corrente autonomista da diplomacia brasileira.

Embora o comportamento brasileiro diante da América do Sul e do Mercosul em particular seja muito diferente em termos de estratégia, qualidade e quantidade das iniciativas de cooperação levadas adiante com potências médias de outros continentes, as percepções da corrente autonomista podem ser identificadas nos dois casos.

Em relação à América do Sul/Mercosul, os avanços são mais notáveis, ainda que convivam com a falta de uma visão consensual destes países sobre princípios que devem nortear a ordem internacional, assim como sobre elementos básicos do regime político e da estratégia de desenvolvimento interna.

O potencial nacionalista de alguns países da região também atua sobre os movimentos de cooperação entre os países do continente. Neste contexto, para o Brasil, a cooperação com estes países, mediada pela construção de uma liderança, significa absorver custos maiores que beneficiem os parceiros menores.

Em relação à cooperação com países de outros continentes, a dinâmica é diferente, mais equilibrada, onde o intercâmbio e a ação coordenada nos foros multilaterais são mais importantes e conseguem influenciar de alguma forma as negociações internacionais.

Nos dois casos, reporta-se à dimensão multifacetada do comportamento brasileiro característica de sua política externa e marca de suas opçôes de cooperação sul-sul. Dentro das estratégias de ação internacional apontadas por Lima, ${ }^{31}$ no primeiro caso, o Brasil assume uma estratégia mais próxima do

31 LIMA, Maria Regina Soares de. A economia política da política externa brasileira: uma proposta de análise, op. cit. 
padrão de hegemonia, enquanto no segundo a iniciativa busca a assunção de um comportamento de liderança na organização da ação coletiva, em cooperação com outros países igualmente system-affecting.

Recebido em 9 de agosto de 2007 Aprovado em 25 de novembro de 2007

\section{Resumo}

O objetivo do artigo é analisar as duas vertentes da cooperação sul-sul adotadas pela política externa brasileira entre 1993 e 2007. Por um lado, o artigo examina a política externa brasileira em face da América do Sul: o Mercosul e a cooperação sul-americana em termos mais gerais que, dentro do arco das atuações externas do país, é o tipo de cooperação sul-sul identificada como prioritária. Por outro lado, dedicará também algumas reflexões para a cooperação do Brasil com outros países considerados emergentes e system-affecting, em outros continentes, como é o caso da África do Sul, Índia, China e, em diferente medida, da Rússia.

\section{Abstract}

The aim of this article is to analyze the two approaches to South-South cooperation evident in Brazilian foreign policy between 1993 and 2007. On one hand the article examines Brazilian foreign policy towards South America. Specifically, cooperation with Mercosur members and South-American cooperation broadly conceptualized. The region is a foreign policy priority among its south-south cooperation activities. On the other hand, this paper reflects on Brazilian cooperation with other emerging and "system-affecting" countries that belong to other continents, such as South Africa, India and China, and to a certain extent, Russia.

Palavras-chave: cooperação Sul-Sul; política externa brasileira, América do Sul, regionalismo e multilateralismo.

Key words: South-South cooperation, Brazilian foreign policy, South America, regionalism and multilateralism. 